\title{
Pharma giants to create databases on gifts to physicians
}

$\mathrm{F}$ acing a national hubbub about the effects of industry money on physician practice and proposed federal legislation mandating that manufacturers of pharmaceutical drugs, devices and biologics disclose financial payments made to physicians to influence prescribing habits, 2 pharmaceutical giants have announced they will publicly report some of their handouts to doctors.

Eli Lilly \& Company and Merck \& Company will next year establish Internet databases listing their payments to doctors. But spokespersons for the firms say the extent of the information to be listed in the databases remains unresolved.

For now, Lilly is proposing to list payments made to physicians who serve as company speakers or advisors, while Merck says it will disclose speaking fees.

Lilly also indicated it hopes to expand the database by 2011 to include all information required by bipartisan legislation introduced by United States Senators Chuck Grassley (Republican-Iowa) and Herb Kohl (Democrat-Wisconsin), which would oblige drug, device and biologics manufacturers to reveal all financial payments, gifts, honoraria, travel and other handouts made to physicians.

Both firms say they have no current plans to include payments to Canadian physicians in their databases, although both anticipate moving to global reporting at an unspecified point in the future.

Grassley and Kohl's Physician Payments Sunshine Act was introduced in 2007 in an attempt to bring industry "influence-peddling out from the shadows." It proposed to create a national, publicly accessible database of all handouts over US\$25, while imposing penalties ranging from US\$10 000 to US\$100 000 (per incident).

The drug industry assailed the legislation, arguing that it would restrict its ability to inform doctors about new drugs and create an "undue burden" because several states had already introduced reporting requirements with differing standards. With the legislation appearing to have stalled, Kohl sought to offset the criticism by cosponsoring a bill that would provide physicians with unbiased information about drugs by

way of academic detailing (CMAJ 2007;176[4]:429-31).

To further nullify opposition, in May 2008, Grassley and Kohl amended the legislation to override state reporting requirements and thus give industry a single, nation-wide reporting standard. They also raised the bar for the financial level of gifts that must be reported (to an aggregate of US\$500 in a calendar year); significantly lowered the penalties for nonreporting (to US\$1000 to $\$ 5000$ per incident, with an annual cap of $\$ 50$ 000); excluded some items from reporting such as product samples, educational materials, and equipment loans, discounts and rebates; and proposed to

\section{Briefly}

President-elect: Dermatologist and former Canadian Medical Association president Dr. Dana Hanson will lead

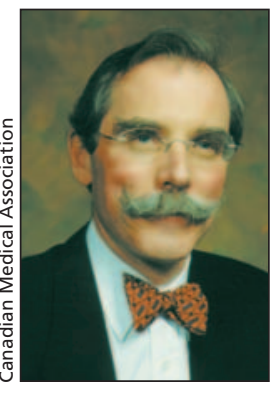

World Medical Association president-elect Dr. Dana Hanson.

\section{Dana Hanson.} sociations since former CMA secretary general Dr. Arthur Peart served as president in 1971.

Banned: Six months after proposing to ban the importation, sale and advertising of polycarbonate baby bottles which contain bisphenol A, Health Canada has announced it will draft regulations to that effect. The move does not prevent the use of bisphenol $\mathrm{A}$ in other consumer products, but the government says it will spend $\$ 1.7$ million over the next 3 years to fund more bisphenol A research. make reporting an annual rather than quarterly requirement.

With the Association of American Medical Colleges having disavowed industry handouts, which are projected at US\$29 billion per year, and the transparency issue having moved centre-stage on the American agenda (CMAJ 2008;178[13]:1651-2 and CMAJ 2008;179[3]:225-6), it's now expected the legislation, which is supported by the American Medical Association, will be taken up by the US Congress in 2009. - Wayne Kondro, CMAJ

DOI:10.1503/cmaj.081669

Spiralling fees: Tuition at Canada's medical schools rose an average $4.6 \%$ for undergraduate medical students in the 2008/09 academic year, Statistics Canada reports. The average fee was $\$ 10392$, trailing only dentistry at $\$ 12906$. Graduate level medical school fees rose $3.4 \%$ to $\$ 6008$, while those for nursing rose $4.3 \%$ to $\$ 4469$ and those for pharmacy rose $5.1 \%$ to $\$ 2006$.

Died: Bernard E. (Woody) Freamo, the first non-physician to serve as secretary general of the Canadian Medical Association, 1992 recipient of CMA's Medal of Honour, and the

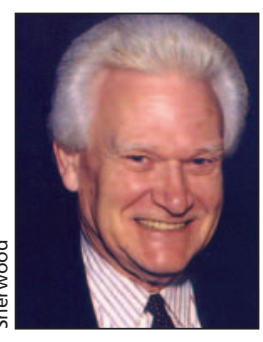

Former CMA secretary general B.E. Freamo. oft-described "father of MD Management," died Oct. 18 at the age of 85. Freamo joined CMA in 1957 to set up a department of economics and became Secretary General in 1982, serving 4 years before becoming executive vice-president of MD Management Ltd. (CMAJ 1986;135:920-5). -Wayne Kondro, CMAJ

DOI:10.1503/cmaj.081668 